REsumo
Frente à mercantilização da
educação, experimentamos uma
epidemia cujo sintoma é a per-
da de coragem dos professores.
Essa se origina na dificuldade
de suportar a angústia gerada
pela distância entre o aluno
empirico e o do passado mitico,
que se interessava espontanea-
mente pelo conbecimento articu-
lado. Seu resultado é a impossi-
bilidade, por parte das novas
gerações, de criar com ele uma
relação que transcenda o mero
uso pragmático. Ao privilegiar
o real, a segunda clinica de
Lacan permite fundar saídas
não moralistas para este impasse
e compreender que, além das que
já estão prontas na cultura, so-
luções singulares e criativas são
necessárias.
Descritores: segunda clinica
lacaniana; Inconsciente real; for-
mação de professores; ensino de
lingua materna; estilos de aula.
a

\section{A PSICANÁLISE E O PROFESSOR QUE AMARELOU}

Isso me leva a pensar que só é ensino verdadeiro aquele que consegue despertar uma insistência naqueles que escutam.

Jacques Lacan (1985, p. 260)

\title{
Introdução
}

$$
\text { -4 sta contribuição, cujo foco é a articula- }
$$
ção possível entre saber e conhecimento na formação de professores, parte de três inspirações distintas. A primeira são os desafios inerentes ao desejo de colaborar na formação de bons professores renovados diariamente, há mais de vinte anos, na lida cotidiana nos cursos de licenciatura. A segunda, os limites a esta pretensão insensata que são mostrados pela psicanálise, campo que se fundou na constatação da existência de uma verdade incômoda em toda possibilidade de articulação de saber

Psicanalista. Docente da Faculdade de Educação da Universidade de São Paulo, coordenadora do Grupo de Estudos e Pesquisa Produção Escrita e Psicanálise (GEPPEP), São Paulo, SP, Brasil. 
(Lacan, 1966/1998). A terceira, por fim, são as descobertas a respeito da formação de professores que temos realizado no âmbito do projeto de pesquisa "Disciplinas da licenciatura voltadas para o ensino de Língua Portuguesa". ${ }^{1}$

Começo por esclarecer o aspecto cromático presente em seu título. Quando alguém empalidece e perde seu viço frente a uma surpresa, diz-se, não sem certa ironia, que ele "amarelou". Uma pessoa que "amarelou" é aquela, portanto, que, por se acovardar, não consegue dar respostas às suas contingências. Escolhi incluir este significante no título deste texto para expressar a seguinte hipótese de trabalho: frente ao que vem sendo chamado de mercantilização da educação em face ao declínio dos saberes, estamos experimentando uma epidemia de uma doença mortífera: o "amarelamento" generalizado dos professores e de seus formadores, "amarelamento" este que parece estar dificultando a missão de preparar as crianças "com antecedência para a tarefa de renovar um mundo comum” (Arendt, 1990, p.247).

Como esta enfermidade funciona? Seu gatilho é a percepção, por parte dos educadores, de que, quando se trata das novas gerações, a realidade empírica é diferente dos seus ideais, sempre remetidos a um passado mítico no qual a maioria dos sujeitos evoluía por meio da normatização edípica. Neste passado mítico, supunha-se que as falhas na relação do sujeito com o conhecimento poderiam ser corrigidas por meio de ações que, direcionando o sujeito para a normatização pulsional, facilitassem a sublimação e, consequentemente, gerassem no sujeito um maior interesse pelos bens culturalmente válidos (Freud, 1930/1996).

Os professores se ressentem na medida de sua incapacidade de abandonar sua expectativa de que a cultura continuasse funcionando como fonte de mal-estar gerado pela decisão de, nas palavras de Freud (Freud, 1930/1996), colocar a cautela antes do gozo. Assim, se melindram ao perceber que, ao que tudo indica, hoje em dia, as instituições não tem sido tão bem sucedidas na tarefa de alienar nosso desejo. Eles amarelam, portanto, quando se dão conta da crescente inutilidade de brandir o conhecimento em uma mão e, na outra, um imperativo para normatizar o gozo, submetendo-o ao desejo.

O "amarelamento" é nefasto para a educação, colocando em risco a sua própria existência. Ele mata o componente libidinal presente no ato de educar e, deste modo, impossibilita que, ao longo da 
formação profissional, se crie uma relação com o conhecimento que transcenda seu mero uso pragmático.

Quando nos dispomos a escutar um professor que "amarelou", a primeira coisa que ele afirma é que está perdido, que não sabe mais o que fazer. Quando entra em sala de aula, se esquece do prazer de viver e abre mão da excitação, do rubor. Ele bem que poderia buscar outros rumos para sua vida, mas não o faz. Descrente e desconfiado, prefere trilhar por caminhos prontos, muito semelhantes àqueles trilhados pelas histéricas do tempo de Freud.

Dê-me um professor que amarelou e eu lhe darei uma pessoa que, independente do seu sexo biológico, ou adota, digamos, uma política de macho, da revolta e da combatividade, ou, permitamo-nos dizer, banca a mulher traída e resignada, que sofre amargamente e exibe sua queixa para quem interessar possa (ou não possa). Em outras palavras, para o professor que amarelou resta ou a belicosidade ou a depressão. A quem amarelou, a menos que alguma contingência o leve a transformar a angústia neurótica em angústia criativa, resta aguardar pela aposentadoria.

Desconhecendo como, em um nível coletivo, podemos curar a epidemia de amarelamento já instalada, prefiro atuar para que, na graduação, o professor em formação seja vacinado. Assim, para mim o pão nosso de cada dia consiste em perguntar: 
Como podemos fazer face a esta verdadeira solução de compromisso na qual o amarelamento consiste?

Abdicando das esperanças de voltar à infância idealizada da educação e inventando soluções que possam nos servir aqui e agora. Elas serão tão múltiplas quanto forem os sujeitos a se responsabilizar por elas. Quanto a mim, tenho procurado gerar desdobramentos para o campo educacional a partir da chamada segunda clínica de Jacques Lacan. Ao atuar por contágio, esta clínica irônica (Miller, 1996), cujos principais elementos são o equívoco e a surpresa, pode consistir em um antídoto contra a epidemia de "amarelamento".

Para tornar mais clara esta ideia, examinemos mais de perto a doença: quem amarelou deixa de ter aquilo que Lacan chamava de "uma relação verídica com o real" (Lacan, 1947/ 2003a). Fecha-se em pretensas soluções narcísicas e estabelece uma prática profissional na qual o aluno não conta ou, o que é pior, é considerado como um estorvo.

Visando a discorrer a respeito de algumas das muitas causas desta catástrofe, no contexto específico da formação de professores de Língua Portuguesa, onde atuo mais diretamente, no que segue vou, primeiramente, mostrar como a formação destes professores tem sido feita na Capital de São Paulo.

Começo por narrar uma tentativa mais ou menos desastrada de encontrar um denominador comum que permitisse descrever como a formação de professores de Língua Portuguesa é feita nas diferentes instituições que, em nossa cidade, oferecem mais de dez mil vagas para ingresso no curso de Letras por ano, com destaque para a Universidade de São Paulo, responsável pela oferta anual de mais de seis mil vagas. Por fim, pretendo concluir a exposição advogando a favor da importância da aula presencial para que, na formação de professores, respeitando-se os devidos limites a esta pretensão, saber e conhecimento venham a ser articulados.

\section{Formação de professores de Língua Portuguesa na cidade de São Paulo}

O que a psicanálise tem a dizer, se chamada como chave de leitura para as práticas de formação de professores nas instituições da capital de São Paulo que oferecem cursos de Letras hoje? Em primeiro lugar, que a significação fálica (Lacan, 1999), aquela que nos permite negociar e obter um ponto de referência mais ou menos passível de ser compartilhado na forma de um modelo a ser seguido por todos, parece ter deixado de ter centralidade.

Não obstante a existência de órgãos dedicados à normatização e ao acompanhamento dos cursos de Letras, fica difícil descrever, com algu- 
ma margem de segurança, quais conteúdos são ou não transmitidos aos futuros professores. Temos cursos com duração de três anos e cursos com duração de seis. Cursos com aulas diárias e cursos nos quais um dia por semana é reservado para o aluno ir ao cinema, cursos nos quais se lê os clássicos nos originais e cursos nos quais se seguem apostilas xerocopiadas onde se encontram os resumos dos principais conteúdos. Aparentemente, mesmo a instância institucional é, de algum modo, organizada ao sabor das pulsões dos sujeitos responsáveis pela tomada de decisões.

$\mathrm{Na}$ direção de uma maior elucidação da afirmação que acabamos de fazer, no âmbito do projeto Disciplinas da licenciatura voltadas para o ensino de Lingua Portuguesa, tomamos as disciplinas do tipo "Metodologia do Ensino da Língua Portuguesa (MELP)" como ponto de verificação no qual pudéssemos estudar a medida na qual, hoje, os saberes pressupostos na formação de professores ainda estão articulados nos cursos oferecidos no Rio Grande do Norte, no Maranhão, em Minas Gerais e em São Paulo.

A parte inicial da pesquisa empírica, iniciada em 2009, permitiu perceber que as flutuações com relação aos aspectos institucionais, teóricos e pragmáticos é tão grande que chega a gerar uma dúvida a respeito da existência de um núcleo comum que permita configurar a existência de uma disciplina MELP, na acepção que é dada por Foucault (1996) a esta palavra.

Lembremos que, para Foucault, ao lado do comentário e do autor, a disciplina é um dos princípios, internos ao dizer, de controle da produção do discurso. Trata-se de uma "espécie de sistema anônimo à disposição de quem quer ou pode servir-se dele" (p. 36) que agiria em favor de lhe fixar os limites pelo jogo de uma identidade que, ao ordenar, classificar e distribuir o discurso, tem a forma de uma reatualização permanente das regras. Tendo um "papel positivo e multiplicador", uma disciplina se definiria por "um domínio de objetos, um conjunto de métodos, um corpus de proposições consideradas verdadeiras, um jogo de regras e de definições, de técnicas e de instrumentos" (p. 30).

Entendendo a dificuldade de chegar a um denominador comum que permitisse isolar este papel positivo em quatro estados da federação, com o auxílio de Natalie Archas Bezerra, pessoalmente me ocupei de uma indagação mais modesta: a partir do estudo dos dados disponíveis no site do Instituto Nacional de Estudos e Pesquisas Educacionais - INEP, ${ }^{2}$ buscamos encontrar estes traços nas 
disciplinas MELP lecionadas nas cinquenta e oito instituições que oferecem cursos de Letras na capital de São Paulo.

Posto isso, é necessário esclarecer que não estávamos em busca de uma homogeneidade que, ao excluir a dimensão do desejo, pudesse aplacar as angústias dos obsessivos de plantão. Gostaríamos, tão somente, chegar a um núcleo comum com relação aos conhecimentos específicos mobilizados nestas disciplinas mesmo que flutuante e sujeito às singularidades de seus docentes - que tornasse possível descrever os modos por meio dos quais os professores de Língua Portuguesa vêm sendo formados em nosso país.

Especifico. Quando se fala de "curso de psicanálise" todo mundo espera escutar termos como "inconsciente", "pulsão", "transferência” e assim por diante. Quando se fala de MELP, ninguém sabe o que vai aparecer. Não há consenso com relação ao título da disciplina, sua inserção departamental, sua carga-horária, seus textos de referência, etc.

Analisando as grades horárias dos diferentes cursos, pudemos perceber que, destas, vinte e uma parecem oferecer disciplinas do tipo MELP. Por que está afirmado aqui que elas "parecem" oferecer estas disciplinas? Porque as grades curriculares não são suficientemente informativas para que tenhamos certeza a este respeito. Ora consta meramente "estágio supervisionado", sem que seja 
possível averiguar se a disciplina é presencial ou não; ora fica difícil, pelo nome da disciplina - como, por exemplo, Prática de Ensino: Trajetória da Práxis - vislumbrar o que lá é feito.

Gostaríamos muito de poder dar uma interpretação otimista a esta enorme variação, inclusive, porque ela seria condizente com a vertente do gozo feminino, da singularidade (Lacan, 1982), mas a existência de três mil professores da Secretaria Estadual da Educação de São Paulo que não acertaram uma única questão sobre a matéria que deveriam dar em sala de aula, nomeados por Gilberto Dimenstein de "Professor Nota Zero" nos leva a suspeitar que está havendo uma dificuldade acentuada para que, durante a graduação, se dê a famosa passagem do discurso comum para o discurso como laço social (Lacan, 1982).

Ao que tudo indica, sob a égide da pós-modernidade, construímos cursos que visavam a estar longe dos efeitos restritivos da famosa incidência de $\mathrm{S} 1$, que se repetindo junto a S2, dava origem ao assujeitamento no discurso do mestre e permitia que, após uma rotação discursiva, mais especificamente, a do discurso universitário, o sujeito emprestasse sua pele para sustentar o saber articulado.

Ao fazê-lo, porém, nos esquecemos de buscar alternativas para gerar, de outra forma, os efeitos organizadores da castração simbólica que se perderam com a instalação do discurso do capitalista (Lacan, 1972). Portanto, neste contexto, não se pode 
falar da articulação entre saber e conhecimento posto que, aqui, o humano é equiparado a um produto forjado pela indústria, qualificado por um mais-de-gozar qualquer. Sendo, assim, os saberes não chegam a se organizar e, muito menos, configurar o savoir-y-faire lacaniano (Lacan, 2007).

Será que estamos fazendo um melhor serviço nesta direção na Universidade de São Paulo? Quem acompanha as formulações de Jacques Lacan, como é o meu caso, sabe o quanto a psicanálise proposta por ele é atenta aos aspectos ligados à inserção institucional dos sujeitos. Lacan sempre deu toda importância ao lugar onde um determinado evento se deu e, mesmo, atribuiu grande relevância aos lugares na interpretação que se faz das falas e dos acontecimentos. Os lugares pré-interpretam, costumava dizer. Assim, interroguemos o "onde".

Quando se trata da formação de professores de línguas, a seguinte divisão é tradicionalmente mantida: por um lado, estão as disciplinas dedicadas ao chamado "núcleo duro" da área, na qual se ensinam seus conteúdos básicos (linguística, literatura, gramática e assim por diante) e do outro, as disciplinas ditas "pedagógicas" (didática, psicologia da educação etc.). Na licenciatura em Letras da Faculdade de Filosofia, Letras e Ciências Humanas - FFLCH, esta divisão se expressa, inclusive, em termos geográficos: as primeiras disciplinas são ministradas no prédio das letras e as segundas no da Faculdade de Educação.

Para os alunos ingressantes no curso de Letras até 2008, para que ingresse na licenciatura, é preciso que tenha cumprido, no mínimo, metade do número de créditos necessários para se formar. Por conta disso, boa parte dos alunos de MELP ou já concluiu o bacharelado ou está em fase de conclusão do curso. Portanto, a seguinte interpretação poderia ser possível: no prédio das Letras se dá a formação inicial e, no da educação, a avançada, na qual os conhecimentos básicos (linguística, literatura, gramática e assim por diante) estão pressupostos.

Não é exatamente assim que isso costuma acontecer. Neste caso, a pré-interpretação que é feita pelos lugares joga contra o tipo de formação de professores que estou propondo neste trabalho. Enquanto nós, os seis professores responsáveis pela disciplina de MELP, acreditamos que, ao longo do ano letivo, poderemos auxiliar os alunos (em média 70 por turma) na delicada tarefa de utilizar as 240 horas que investem em MELP, ${ }^{3}$ para, a transformar as infor- 
mações acumuladas ao longo do curso de Letras em conhecimentos passíveis de serem compartilhados com as novas gerações, eles, os alunos, costumam atravessar os quilômetros que separam o bacharelado e a literatura no mínimo desconfiados de que o discurso adocicado que esperam escutar dos pedagogos é tão inútil quanto aborrecido.

Demover os futuros professores desta interpretação inicial a respeito da própria formação não é uma tarefa fácil e, se o docente acaba ganhando a parada de persuadir seus alunos, isso se deve a sua capacidade que a sua própria paixão tem de fazer com que seus alunos abdiquem das matrizes de interpretação que trazem no início do curso.

Oferecer algo mais sedutor do que uma matriz de sentido já cristalizada é uma necessidade que se torna ainda mais pronunciada quando os estágios são iniciados e o futuro professor tem seu primeiro contato com as condições de trabalho das escolas públicas.

A complicação começa já no estágio de observação. Decepcionados com a recepção pouco calorosa dos professores veteranos e grandemente angustiados com a apatia e desinteresse dos alunos das escolas do ensino fundamental e médio, a primeira reação dos estagiários da USP não é muito diferente da neurótica histérica: Eu não quero saber de nada disso, eles parecem dizer ora com suas palavras ora com a linguagem corporal.
Frente à prova de realidade na qual o estágio de regência se configura para os futuros professores, os conhecimentos estudados durante o bacharelado tendem a ser ou supervalorizados, à custa da degradação daqueles que serão seus futuros alunos ou degradados, à custa da supervalorização de fenômenos de moda.

No primeiro caso, lá pelo meio do curso de MELP, em face ao abismo existente entre o seu ideal de aluno e aquilo que encontra em sala de aula, o professor em formação desenvolve reações - bastante avessas ao politicamente correto - que expressa com grande carga de emoção. Um exemplo: Eu não acho que mereça o nome de "ser humano" quem nunca leu Machado de Assis! - diz uma ruiva bonita, inteligente e, ao menos aparentemente, bastante empenhada em se tornar uma boa professora de Língua Portuguesa. Das pessoas que eventualmente gostem de ler outras coisas ela não quer saber.

No segundo, identificados aos jovens alunos que têm a oportunidade de conhecer e, muitas vezes seduzidos pelas promessas de gozo vislumbradas nas propostas educacionais aparentemente de vanguarda, eles querem incluir tudo e mais um pouco na sala de aula, em detrimento dos conhecimentos escolares. Para que ensinar ortografia se o Word corrige? A onde agora é a expressão por meios não verbais, advoga um jovem negro tão cheio de idéias quan- 
to de músculos. Ele, que corre atrás de novidade em novidade, não quer saber dos conhecimentos que estudou em seu próprio curso.

O que estes jovens tão distintos têm em comum? Frente ao confronto com a realidade da escola, ao invés de insistir na direção de uma articulação possível entre saber e conhecimento, eles amarelaram. Levará algum tempo, e muita coragem, para que possam mudar de posição. Isso, se tiverem boas aulas.

\section{A aula especificamente voltada para a formação de professores}

Para mim, se um analista se forma em sua análise pessoal, um bom professor se forma na aula, o lócus historicamente privilegiado para a transmissão de um amor pela cultura socialmente validada. Do mesmo modo que nem toda análise pessoal tem como sua última consequência o advento de um analista, nem todo agrupamentos de aluno com um docente na frente gera uma ação que mereça o nome de aula.

Posto isso, torna-se necessário inicialmente explicitar o que estou chamando de "aula". Para que um determinado evento escolar possa merecer esse nome, é necessário que um agrupamento mais ou menos aleatório de pessoas confinado em um espaço físico transforme-se em um grupo permeável ao conhecimento e, não só se abra a sua parcela que já está pronta como decida se empenhar na construção da parcela que não está.

Nesta acepção, o que define a existência de uma "aula", portanto, não é o fato de que determinado conteúdo tenha ou não sido tratado, mas sim, que uma mutação muito particular tenha ocorrido: a famosa passagem do discurso comum para o discurso como laço social que, na figura inicial do discurso de mestre, está pressuposta por Lacan em ao menos dois de seus Seminários (Lacan, 1992; 1982).

No meu modo de ver as coisas, o personagem mais importante para que esta mutação se dê é o professor, no caso, o formador de professores. Ao se sustentar em um lugar que é, ao mesmo tempo, interno e externo ao grupo de alunos, e, por esse motivo, poder dar relevo ao famoso significante-mestre, ele funda a aula enquanto um espaço onde é possível um constante questionamento a respeito do estado atual de elaboração de cada um a respeito do objeto de estudo.

Antes que se diga que isso é fácil de falar e difícil de fazer, permito-me manter esta meta no plano do ideal. Como seria o docente ideal, aquele cuja ação seria fundamental para a formação dos bons professores? Penso que, em um velho texto de Lacan (1947/2003a), publicado originariamente em 1947, poderíamos encontrar elementos para descrevê-lo.

Narrando sua visita, por cinco semanas, a Londres (em maio de 
1945, logo após as comemorações pelo término da Segunda Guerra Mundial), Lacan estava fascinado pelos ingleses a quem, ao contrário dos seus compatriotas, puderam, durante a guerra, não ceder de uma intrepidez que repousa "numa relação verídica com o real" (p.106).

Por este motivo, buscou inteirarse dos detalhes de várias experiências dos psiquiatras ingleses que, em sua avaliação, foram determinantes para que a Inglaterra pudesse ganhar a guerra. Determinado observar de perto como trabalhavam as pessoas de algum modo protegidas das modalidades de defesa dos neuróticos contra a angústia, Lacan encontrou em Wilfred Bion um exemplo de pessoa que não varre o que incomoda para baixo do tapete.

Ao analisar o método adotado por Bion em sua atividade em um hospital militar, onde empreenderam o serviço de "reeducação" de quatrocentos soldados cuja indisciplina tinha impossibilitado a utilização no exército durante a Segunda Guerra, Lacan afirmou que estes homens acabaram por ser bem sucedidos porque, dentre outros fatores, tinham encontrado em Bion um elemento para transformar o "agregado de irredutíveis", a quem Lacan chama de avesraras, em uma tropa em marcha.

O que eles encontraram? Encontraram em Bion alguém que não se acovardou nem frente a diferença geracional nem frente a distância existente entre as pessoas com quem ti- 
nha de trabalhar e as suas expectativas. Encontraram, portanto, alguém que, para além das práticas standard e modismos de seu tempo, improvisou uma conduta especificamente planejada para funcionar com aqueles com quem tinha de trabalhar.

Eu cito a descrição de Lacan:

[em Bion eles encontraram...] um líder em quem sua experiência com os homens permita fixar com precisão a margem a ser dada às fraquezas deles, e que possa lhes manter os limites com sua autoridade, isto é, pelo fato de cada um saber que, uma vez assumida uma responsabilidade, ele não 'amarela' (Lacan, 1947/2003a, p.113, itálico nosso).

Foi, evidentemente, este excerto que inspirou o título do presente trabalho.

\section{Considerações finais}

Como alguém pode, nos dias de hoje, conseguir a façanha de, respeitando-se as devidas proporções, sustentar uma prática que se aproxime da exercida por Bion? Penso que, para poder se sustentar neste lugar, o professor precisa ter se beneficiado de uma formação cuja configuração é bastante complexa, posto que, de algum modo, deve coadunar a singularidade de suas escolhas pessoais com a universalidade do conhecimento articulado.

Assim, ela deve fornecer ao futuro professor os meios para que, em seu fazer cotidiano, ele possa fazer duas coisas: a) colocar o saber inconsciente a serviço da tarefa de fazer com que as novas gerações possam se relacionar com o conhecimento historicamente construído na sua área de atuação; e b) compreender que, para além de toda articulação possível, o real irrompe, demandando a constante invenção de soluções singulares e criativas.

Reconheço que, em tempos nos quais a técnica parece estar cada vez mais tamponando a dúvida subjetiva, esta tese ousada está sujeita a todo tipo de dificuldade institucional. Mas esclareço: sua sustentação é independente das escolhas pessoais do professor por esta ou aquela área de concentração, esta ou aquela abordagem teórico-metodológica. Aqui, não se trata de melhor ou pior, mas de mais ou menos apaixonante, mais ou menos passível de gerar entusiasmo. 
Lembremos que, à medida que se aproxima da formulação de sua segunda clínica, a clínica do real, Lacan (1973/2003b) valoriza cada vez mais o entusiasmo como um traço positivo. Longe de apontar para uma pessoa ingênua, que, por conta de sua baixa capacidade de crítica, não seria capaz de perceber os entraves da realidade empírica, o entusiasmo é índice de um sujeito que é capaz de se responsabilizar por suas escolhas.

Se eu tivesse que escolher um único traço definidor do professor que não amarelou, ele não se voltaria às suas reclamações e, mesmo, às confissões de suas incertezas e inseguranças. Não ter certezas fechadas faz parte da constituição de um sujeito saudável. Assim, ao que parece, o antídoto para a epidemia de "amarelamento" não está nem no avanço da ciência e nem no progresso técnico. Localiza-se em instância mais intangível e, paradoxalmente, menos dispendiosa: em nossa capacidade pelo entusiasmo.

\section{PSYCHOANALYSIS AND THE TEACHER WHO HAS CHICKENED OUT}

\footnotetext{
Abstract

Given the education's commodification, we are in train to experience an epidemic which symptom is the teacher's loss of courage. It begins withthe difficulty to bare the anguish generated by the distance between the empiric student and the one from the mythic past, who was spontaneously interested by articulated
}

knowledge. Its result is the impossibility, by the new generations, to create a relationship with knowledge that goes far beyond its pragmatic use. As it gives privilege to real, Lacan's second clinic allows the foundation of non-moralistic solutions to this impasse. Also, it allows us to understand that, besides the solutions that are ready in our culture, singular and creative solutions are necessary.

Index terms: lacanian second clinic; real unconscious; teacher formation; mother tongue teaching; classes styles.

\author{
EL PSICOANÁLISIS Y EL PROFESOR \\ QUE SE ACOBARDÓ.
}

\section{Resumen}

Frente a la comercialización de la educación, experimentamos una epidemia cuyo sintoma es la pérdida del coraje de los profesores. Esto se origina en la dificultad para soportar la angustia que se genera por la distancia entre el alumno empírico y aquel del pasado mítico, que se interesaba espontáneamente por el conocimiento articulado. El resultado es la imposibilidad, por parte de las nuevas generaciones, de crear con el conocimiento una relación que trasciende su mero uso pragmático. Al privilegiar el real, la segunda clinica de Lacan permite encontrar salidas no moralistas a este conflicto y comprender que, más allá de las que están listas en la cultura, se necesitan soluciones singulares y creativas.

Palabras clave: segunda clínica lacaniana; Inconsciente real; formación del profesorado; enseñanza de la lengua materna; estilos de clase.

\section{REFERÊNCIAS}

Arendt, H. (1990). Entre o passado e o futuro. São Paulo, Perspectiva.

Dimenstein, G. (2009, 08 de fevereiro). Professor nota zero. Texto recuperado em 13 nov. 2009: http://www1.folha.uol. com.br/folha/pensata/gilberto dimenstein/ult508u500752.shtml. 
Foucault, M. (1996). A ordem do discurso. São Paulo: Edições Loyola.

Freud, S. (1996). O mal estar na civilização. In S. Freud, Edição standard brasileira das obras psicológicas completas de Sigmund Freud (J. Salomão, trad., Vol. 21, pp. 65148). Rio de Janeiro: Imago. (Trabalho original publicado em 1930)

Lacan, J. (1972). Du discours psychanalytique. Conférence à l'université de Milan. Texto recuperado em 21 de abr. 2011: http://espace.freud.pagesperso-orange.fr/topos/psycha/psysem/italie.htm

Lacan, J. (1982). O seminário, livro 20: mais, ainda, 1972-1973. Rio de Janeiro: Jorge Zahar Editor.

Lacan, J. (1985). O seminário, livro 2: o eu na teoria de Freud e na técnica da psicanálise, 1954-1955. Rio de Janeiro: Jorge Zahar.

Lacan, J. (1992). O seminário. livro 17: o avesso da psicanálise, 1968-1969. Rio de Janeiro: Jorge Zahar.

Lacan, J. (1998). A ciência e a verdade. In J. Lacan, Escritos (pp. 869-892). Rio de Janeiro: Jorge Zahar. (Trabalho original publicado em 1966)

Lacan, J. (1999). O seminário, livro 5: as formações do inconsciente, 1957-1958. Rio de Janeiro: Jorge Zahar.

Lacan, J. (2003a). A psiquiatria inglesa e a guerra. In J. Lacan, Outros escritos (pp. 106- 126). Rio de Janeiro: Jorge Zahar Editor. (Trabalho original publicado em 1947)

Lacan, J. (2003b). Nota italiana. In J. Lacan, Outros escritos (pp.311-315). Rio de Janeiro: Jorge Zahar. (Trabalho original publicado em 1973)

Lacan, J. (2007). O seminário, livro 23: o sinthoma, 1975-1976. Rio de Janeiro: Jorge Zahar Editor, 2005.

Miller, J-A. (1996). Clínica irônica. In J-A Miller, Matemas I (pp.190-200). Rio de Janeiro: Jorge Zahar Editora. 


\section{NOTAS}

1 Trata-se de um projeto de pesquisa que toma as disciplinas de licenciatura especificamente voltadas para os conteúdos diretamente ligados ao ensino da Língua Portuguesa como objeto. Aprovado no Edital Procad-NF N 08/2008 da CAPES, ele tem sido levado a cabo por uma equipe de trinta pessoas (entre docentes, voluntários e bolsistas) vinculada a três universidades parceiras: Universidade Estadual do Rio Grande do Norte/ Campus Pau dos Ferros; Universidade Federal do Maranhão e Universidade de São Paulo.

2 Disponível em: http://www.educacaosuperior.inep.gov.br/funcional/ lista_cursos.asp. Acesso em: 10/10/2008.

3 Mais especificamente 120 horas de aula, organizadas em 15 encontros por semestre, e mais 120 horas de estágio, dentre as quais 40 são dedicadas à regência.

riolfi@usp.br

Av. Nossa Senhora Assunção, 675/12 E. 05359-001 - São Paulo - SP - Brasil.

Recebido em junho/2011. Aceito em agosto/2011. 